\title{
BMJ
}

\section{Delivering the diabetes education and self management for ongoing and newly diagnosed (DESMOND) programme for people with newly diagnosed type 2 diabetes: cost effectiveness analysis}

\author{
M Gillett, research fellow, ${ }^{1} \mathrm{H}$ M Dallosso, senior research associate, ${ }^{2} \mathrm{~S}$ Dixon, reader in health economics, ${ }^{1}$ \\ A Brennan, professor of health economics and decision science, ${ }^{1}$ M E Carey, national director, ${ }^{2} \mathrm{M}$ J Campbell, \\ professor of medical statistics, ${ }^{1} \mathrm{~S}$ Heller, professor of clinical medicine, ${ }^{3} \mathrm{~K}$ Khunti, professor of diabetes \\ medicine, ${ }^{4} \mathrm{~T}$ C Skinner, associate professor, ${ }^{5}$ M J Davies, professor of diabetes medicine ${ }^{6}$
}

${ }^{1}$ School of Health and Related Research (ScHARR), University of Sheffield, Sheffield

2DESMOND Project Office, University Hospitals of Leicester NHS Trust, Leicester

${ }^{3}$ Academic Unit of Diabetes, Endocrinology and Metabolism, School of Medicine and

Biomedical Sciences, University of Sheffield, Sheffield

${ }^{4}$ Department of Health Sciences, University of Leicester, Leicester

${ }^{5}$ Combined Universities Centre for Rural Health, Geraldton, Australia

${ }^{6}$ Department of Cardiovascular Medicine, University of Leicester, Leicester Royal Infirmary, Leicester

Correspondence to: M Gillett m.gillett@sheffield.ac.uk

Cite this as: BMJ 2010;341:C4093 doi:10.1136/bmi.c4093

\section{ABSTRACT}

Objectives To assess the long term clinical and cost effectiveness of the diabetes education and self management for ongoing and newly diagnosed (DESMOND) intervention compared with usual care in people with newly diagnosed type 2 diabetes.

Design We undertook a cost-utility analysis that used data from a 12 month, multicentre, cluster randomised controlled trial and, using the Sheffield type 2 diabetes model, modelled long term outcomes in terms of use of therapies, incidence of complications, mortality, and associated effect on costs and health related quality of life. A further cost-utility analysis was also conducted using current "real world" costs of delivering the intervention estimated for a hypothetical primary care trust.

Setting Primary care trusts in the United Kingdom.

Participants Patients with newly diagnosed type 2 diabetes.

Intervention A six hour structured group education programme delivered in the community by two professional healthcare educators.

Main outcome measures Incremental costs and quality adjusted life years (QALYs) gained.

Results On the basis of the data in the trial, the estimated mean incremental lifetime cost per person receiving the DESMOND intervention is $£ 209$ (95\% confidence interval -£704 to £1137; €251, -€844 to €1363; \$326, $-\$ 1098$ to $\$ 1773)$, the incremental gain in QALYs per person is 0.0392 ( -0.0813 to 0.1786$)$, and the mean incremental cost per QALY is $£ 5387$. Using "real world" intervention costs, the lifetime incremental cost of the DESMOND intervention is $£ 82$ ( $-£ 831$ to $£ 1010)$ and the mean incremental cost per QALY gained is $£ 2092$. A probabilistic sensitivity analysis indicated that the likelihood that the DESMOND programme is cost effective at a threshold of $£ 20000$ per QALY is $66 \%$ using trial based intervention costs and $70 \%$ using "real world" costs. Results from a one way sensitivity analysis suggest that the DESMOND intervention is cost effective even under more modest assumptions that include the effects of the intervention being lost after one year.

Conclusion Our results suggest that the DESMOND intervention is likely to be cost effective compared with usual care, especially with respect to the real world cost of the intervention to primary care trusts, with reductions in weight and smoking being the main benefits delivered.

\section{INTRODUCTION}

Type 2 diabetes mellitus affects around 5\% of people in European populations and is responsible for a disproportionate use of health service resources. ${ }^{1}$ In the short term, diabetes can be accompanied by various symptoms such as fatigue, and in the long term it can lead to serious complications such as blindness, renal failure, and amputation. ${ }^{2}$ Furthermore, diabetes is associated with increased morbidity and premature death from cardiovascular diseases, including stroke and myocardial infarction. Lifestyle advice on diet and exercise is at the core of first line management of diabetes, either alone or with concomitant use of drugs such as metformin. ${ }^{3}$ However, patients find it difficult to implement and sustain lifestyle advice given by healthcare professionals. ${ }^{4}$

The national service framework for diabetes and the 2008 National Institute for Health and Clinical Excellence diabetes guideline ${ }^{5}$ explicitly state that all primary care trusts should offer structured education programmes to people with type 2 diabetes from the point of diagnosis. The diabetes education and self management for ongoing and newly diagnosed (DESMOND) intervention for people with newly diagnosed type 2 diabetes was one of the first programmes to meet the criteria for suitable education programmes laid down by the National Institute for Health and Clinical Excellence and is currently available in at least 80 primary care trusts in England and Scotland. The programme, which is facilitated by registered healthcare 
professionals trained as educators, comprises six hours of contact time during a full day or as two half day sessions. The curriculum focuses on lifestyle factors, such as food choices and physical activity, and cardiovascular risk factors.

Before the trial of the DESMOND programme, which started in $2004,{ }^{6}$ there was no evidence that structured education from the point of diagnosis provides added benefit for patients beyond usual care. The cluster randomised trial took place in 13 primary care sites (162 practices) involving 1109 patients with type 2 diabetes who were referred within four weeks of diagnosis. A total of 824 (74\%) individuals consented and were assigned to either the DESMOND intervention or standard care on the basis of which study arm their practice was randomised to. Those randomised to the intervention completed the structured group education programme within 12 weeks. The study design, baseline characteristics of the patients, and changes in biomedical, lifestyle, and psychosocial measures over 12 months in the $91 \%$ of participants with follow-up data at 12 months have been reported previously. ${ }^{6-8}$ Analyses of the trial data showed improvements in weight, smoking cessation, illness beliefs, and depression scores in patients who received the intervention compared with those on standard care. ${ }^{6}$

To date, there has been no economic evaluation of the DESMOND intervention, or any similar education intervention in the United Kingdom, to assess whether the benefits reported in our trial represent a cost effective return on the intervention compared with either no education or ad hoc and unevaluated education (that is, usual care). This study examines the cost and utility of the DESMOND programme when assessed against the National Institute for Health and Clinical Excellence's cost effectiveness acceptability threshold of $£ 20000$ (€23 982; \$31 191) per quality adjusted life year (QALY), ${ }^{9}$ based on intervention costs both from the earlier trial and as currently being implemented in a UK primary care setting.

\section{METHODS}

The costs of delivering the DESMOND programme and its effects on health related quality of life, particularly in relation to reductions in weight and smoking, will accrue over the long term, and, therefore, an analysis using only the 12 month outcomes from our previous trial would be inappropriate. We incorporated the 12 month trial results into a long term model of diabetes - the Sheffield type 2 diabetes model - that accounts for the long term effects of the intervention on smoking and weight as well as on the biomedical measures (that is, levels of glycated haemoglobin $\left(\mathrm{HbA}_{1 \mathrm{c}}\right)$, cholesterol, and systolic blood pressure) that affect comorbidities of diabetes, such as cardiovascular disease, retinopathy, neuropathy, and renal complications.

The trial based inputs we planned to use in the diabetes model needed to take account of the clustered nature of the data (that is, randomisation was at practice level). ${ }^{6}$ Consequently, these inputs were analysed using robust generalised estimating equations, ${ }^{10}{ }^{11}$ with exchangeable correlation structure. For binary outcomes, a logit link with a binomial distribution for the outcome was used. For continuous outcomes, an identity link with a normal distribution was used. For ordinal outcomes, we used an ordinal regression model with proportional odds assumption, adjusted for clusters. ${ }^{12}$ As well as adjusting for clustering, additional covariates were incorporated into the statistical models as deemed appropriate for the specific analyses being undertaken. Analyses were done using STATA 10.0/SE for Windows. Missing outcomes were not replaced and analyses were carried out on an intention to treat basis.

The overall approach to the economic evaluation is in line with the reference case methods for National Institute for Health and Clinical Excellence technology appraisals. The economic evaluation component used an NHS and personal social services perspective for costs, and health outcomes measured in QALYs were based on EQ-5D values. Both costs and QALYs were discounted at $3.5 \%$ per annum in line with current National Institute for Health and Clinical Excellence guidance. $^{9}$

\section{Estimates of cost}

\section{Costs of delivering the DESMOND programme}

We undertook a bottom up costing exercise to calculate the average cost per patient of delivering the DESMOND programme within the trial (table 1). Some items of expenditure, such as the training of educators and non-consumable purchases for the course (for example, food models, display boards), provided resources for use over a much longer period than the trial. Research costs, including one additional general practitioner visit, were excluded from the costs of the programme. Non-recurrent costs were spread over a three year period using annuitisation at a rate of 3.5\% a year, with the equivalent annual cost being included in the calculation of the cost of the course.

The costs of delivering the programme in primary care have changed since the trial because the DESMOND team has a better appreciation of resource requirements and was able to capture the economies of scale through widespread delivery of the programme (for example, more participants per educator). Therefore, we also estimated the "real world" cost of the components of the programme for a hypothetical primary care trust with an average population of 329550 patients. We also assumed a total of 56 DESMOND courses would be run each year by three educators and an average of 10 patients per course.

\section{Other within trial costs}

Trial data were used to identify use of drugs and use of general practitioners' and other primary care professionals' time over 12 months. Medication use was recorded at four month intervals in the trial, so we estimated an individual's aggregated drug use over the 12 months of the trial from the usage recorded at 
Table $1 \mid$ Costs of the DESMOND intervention

\begin{tabular}{|c|c|c|c|c|c|}
\hline \multirow{2}{*}{$\begin{array}{l}\text { Category and details of } \\
\text { cost }\end{array}$} & \multirow{2}{*}{$\begin{array}{l}\text { Level cost } \\
\text { incurred }\end{array}$} & \multicolumn{2}{|c|}{$\begin{array}{c}\text { Cost based on the trial of the DESMOND } \\
\text { intervention } 6\end{array}$} & \multicolumn{2}{|c|}{ Cost in the "real world" } \\
\hline & & Cost $(£)$ & Basis & Cost $(£)$ & Basis \\
\hline \multicolumn{6}{|c|}{ Delivery of the DESMOND intervention } \\
\hline Educators & $\begin{array}{l}\text { DESMOND } \\
\text { course }\end{array}$ & 531 & $\begin{array}{l}\text { Two educators per course for two days per } \\
\text { course, at } £ 128 \text { per day }\end{array}$ & 479 & $\begin{array}{c}\text { One educator per course for one day } \\
\text { per course, at top of band } 6 \text { ( } £ 39701 \\
\text { per year including costs) }\end{array}$ \\
\hline Refreshments & Patient & 4 & $\begin{array}{l}\text { Average of } £ 3 \text { per patient for a one day } \\
\text { course or } £ 1.50 \text { if course split over two days; } \\
\text { scaled up to include cost of guests } \\
\text { (assumed ratio of patients to guests }=5: 3 \text { ) }\end{array}$ & 1 & $\begin{array}{l}\text { Estimate (less than during trial as no } \\
\text { lunch provided in "real world") }\end{array}$ \\
\hline Handbook & Patient & 12 & - & 5 & - \\
\hline $\begin{array}{l}\text { Disposable course } \\
\text { materials (for example, } \\
\text { flipcharts, worksheets) }\end{array}$ & $\begin{array}{l}\text { DESMOND } \\
\text { course }\end{array}$ & 6 & - & 8 & - \\
\hline $\begin{array}{l}\text { Course materials (for } \\
\text { example, food, models) }\end{array}$ & $\begin{array}{l}\text { Primary care } \\
\text { trust* }\end{array}$ & 630 & - & 0 & $\begin{array}{l}\text { Included in } £ 675 \text { starter pack from } \\
\text { DESMOND central office }\end{array}$ \\
\hline $\begin{array}{l}\text { Non-perishable "food } \\
\text { models" }\end{array}$ & $\begin{array}{l}\text { Primary care } \\
\text { trust }\end{array}$ & $\begin{array}{l}\text { Covered } \\
\text { within } \\
\text { "sundries" } \\
\text { cost below }\end{array}$ & - & 18 & - \\
\hline $\begin{array}{l}\text { Leaflets and postage (for } \\
\text { example, letter } \\
\text { confirming date, letter to } \\
\text { practice) }\end{array}$ & Patient & 2 & - & 2 & - \\
\hline Venue & $\begin{array}{l}\text { DESMOND } \\
\text { course }\end{array}$ & $\begin{array}{c}\text { Not } \\
\text { applicable }\end{array}$ & $\begin{array}{l}\text { Included within } £ 400 \text { sundry payment to } \\
\text { primary care trust }\end{array}$ & 25 & $\begin{array}{c}\text { Estimate based on feedback from } \\
\text { primary care trusts; can vary by a } \\
\text { large amount depending on local } \\
\text { circumstances }\end{array}$ \\
\hline Sundries & $\begin{array}{l}\text { Primary care } \\
\text { trust }\end{array}$ & 400 & None assumed research cost & 0 & Itemised above \\
\hline \multicolumn{6}{|l|}{ Training costs } \\
\hline $\begin{array}{l}\text { Courses to train } \\
\text { educators }\end{array}$ & Trial* $^{\star}$ & $30224 \dagger$ & Training days & $\begin{array}{l}\text { Included in fees (see "Programme fees } \\
\text { from DESMOND central office" below) }\end{array}$ & - \\
\hline Sundry course resources & Trial* $^{\star}$ & 9 & - & $\begin{array}{l}\text { Included in fees (see "Programme fees } \\
\text { from DESMOND central office" below) }\end{array}$ & - \\
\hline \multicolumn{6}{|c|}{ Quality assurance of educators } \\
\hline Educator time and travel & Not applicable & 0 & $\begin{array}{l}\text { Quality assurance done while courses } \\
\text { running }\end{array}$ & $\begin{array}{l}\text { Included in fees (see "Programme fees } \\
\text { from DESMOND central office" below) }\end{array}$ & - \\
\hline $\begin{array}{l}\text { Quality assurers'time and } \\
\text { travelf }\end{array}$ & Educator* & 181 & $\begin{array}{l}\text { Two educators were assessed at each visit; } \\
\text { total } 11 \text { visits }\end{array}$ & $\begin{array}{l}\text { Included in fees (see "Programme fees } \\
\text { from DESMOND central office" below) }\end{array}$ & - \\
\hline \multicolumn{6}{|c|}{ Programme fees from DESMOND central office } \\
\hline $\begin{array}{l}\text { Training three educators } \\
\text { (year one) }\end{array}$ & $\begin{array}{l}\text { Primary care } \\
\text { trust* }^{\star}\end{array}$ & $\begin{array}{l}\text { Not } \\
\text { applicable }\end{array}$ & - & 2385 & $\begin{array}{l}£ 360 \text { each for three educators per } \\
\text { primary care trust per year }\end{array}$ \\
\hline $\begin{array}{l}\text { Quality assurers' fees and } \\
\text { travel (years two and } \\
\text { three) }\end{array}$ & $\begin{array}{l}\text { Primary care } \\
\text { trust* }^{\star}\end{array}$ & $\begin{array}{c}\text { Not } \\
\text { applicable }\end{array}$ & - & 1001 & - \\
\hline $\begin{array}{l}\text { Annual fee for } \\
\text { accreditation (year two } \\
\text { onwards) }\end{array}$ & $\begin{array}{l}\text { Primary care } \\
\text { trust* }\end{array}$ & $\begin{array}{c}\text { Not } \\
\text { applicable }\end{array}$ & - & 300 & $£ 50$ per educator per year \\
\hline Starter pack & $\begin{array}{l}\text { Primary care } \\
\text { trust* }\end{array}$ & $\begin{array}{l}\text { Not } \\
\text { applicable }\end{array}$ & - & 675 & - \\
\hline Programme fee§ & $\begin{array}{l}\text { Primary care } \\
\text { trust* }\end{array}$ & $\begin{array}{c}\text { Not } \\
\text { applicable }\end{array}$ & - & 4943 & $\begin{array}{l}0.015 p \text { per patient in primary care } \\
\text { trust per year }\end{array}$ \\
\hline \multicolumn{6}{|c|}{ Coordination and indirect costs incurred by primary care trusts } \\
\hline $\begin{array}{l}\text { Coordination time (for } \\
\text { example, booking } \\
\text { patients on course, } \\
\text { sending letters, booking } \\
\text { rooms) }\end{array}$ & $\begin{array}{l}\text { DESMOND } \\
\text { course }\end{array}$ & 127 & Expected to do five courses in trial & 59 & $\begin{array}{l}3.5 \text { hours per course at Band } 4 \text { ( } 20 \\
821 \text { per year including costs) }\end{array}$ \\
\hline \multicolumn{6}{|c|}{ Within trial central office costs (delivery only) } \\
\hline $\begin{array}{l}\text { Element to annuitise (for } \\
\text { example, arranging } \\
\text { training) }\end{array}$ & Trial* $^{*}$ & 742 & 0.5 days per month for 15 months & Not applicable & - \\
\hline $\begin{array}{l}\text { Element relating to trial } \\
\text { period }\end{array}$ & Trial & 742 & - & Not applicable & - \\
\hline
\end{tabular}

DESMOND, diabetes education and self management for ongoing and newly diagnosed.

Educators' travel costs were deemed to be negligible because these costs would not be claimed if the course was held locally or no further than the distance to workplace.

*The benefits of these resources accrue over several years. We conservatively spread out such costs over a period of three years.

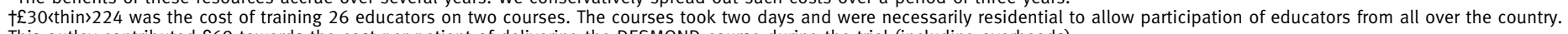

This outlay contributed $£ 69$ towards the cost per patient of delivering the DESMOND course during the trial (including overheads).

fFor the trial, this cost was averaged across 13 primary care trusts because not all trusts received a quality assurance visit.

$\S$ Dependent on size of primary care trust. Total calculated from average primary care trust size. 
baseline, month four, month eight, and month 12. Unit costs of drugs were obtained from the NHS Information Centre for Health and Social Care's prescription cost analysis $2007^{13}$ and a weighted average of the most frequently used drugs in each class was used. Unit costs for visits to a general practitioner and other consultations were obtained from the Personal Social Services Research Unit's unit costs of health and social care $2007 .{ }^{14}$

Differences between the control and the intervention group in drug use and use of NHS resources are shown in table 2 . These costs were then combined and reanalysed to adjust for clustering and covariates that were relevant to both drug and resource.

\section{Unit costs relating to long term complications}

Unit costs relating to long term complications were obtained from a variety of published sources, the most significant ones for this evaluation being costs of events relating to cardiovascular disease and comorbidities, which were obtained from United Kingdom Prospective Diabetes Study number 65 (UKPDS 65). ${ }^{15}$ These data were adjusted to 2008 levels using the Hospital and Community Health Services Pay and Price Index. ${ }^{14}$

Effects of the intervention at month 12 of the trial Biomedical measures

In the long term model described later, the differences between biomedical measures at baseline and these characteristics at 12 months in the trial of the
DESMOND intervention were incorporated into the characteristics of patients at baseline, as shown in table 3 . Lifestyle changes might not be sustained without an ongoing maintenance intervention, so we assumed that the effects observed would be completely lost three years after the end of the intervention.

\section{Smoking}

Smoking status at entry to the long term model was based on the conditional probabilities shown in table 4 , which relate final smoking status in the trial of the DESMOND intervention to that at baseline. This shows that, compared to patients in the control arm, there was a greater probability of patients in the intervention arm stopping smoking, and less chance of non-smokers starting smoking. We obtained annual relapse rates from an analysis ${ }^{16}$ of British Household Panel Survey data and used these to model the probability that a patient who had quit smoking during the trial subsequently relapses. We calculated a relapse rate of $19.6 \%$ after one year of abstinence, which decreases to $3.8 \%$ at five years and $1.6 \%$ at 12 years.

\section{Weight}

After adjustment for age, gender, $\mathrm{HbA}_{1 \mathrm{c}}$, smoking status, use of drugs known to affect weight (for example, oral hypoglycaemic agents, diuretics), baseline values, and clustering, there was a $-1.26 \mathrm{~kg}(95 \% \mathrm{CI}-2.19$ to $-0.34)$ difference in weight between the intervention arm and the control arm at 12 months. This effect may not be sustained without an ongoing maintenance

Table 2 Use of medication and NHS resources in the trial of the DESMOND intervention, unit costs, and overall cost differences

\begin{tabular}{|c|c|c|c|c|c|}
\hline & Control (unadjusted) & $\begin{array}{l}\text { Intervention } \\
\text { (unadjusted) }\end{array}$ & $\begin{array}{l}\text { Adjusted difference* } \\
\text { (mean }(95 \% \mathrm{CI}))\end{array}$ & Unit cost ( $£$ per day) & $\begin{array}{c}\text { Effect of difference in } \\
\text { usage on cost }(£)\end{array}$ \\
\hline \multicolumn{6}{|c|}{ Medication use (average number of months use per patient during the 12 months of the trial) } \\
\hline Metformin & 3.04 & 3.30 & $-0.35(-0.92$ to 0.22$)$ & $0.13^{13}$ & -1.38 \\
\hline Sulphonylureas & 0.80 & 0.79 & $-0.15(-0.48$ to 0.18$)$ & $0.11^{13}$ & -0.50 \\
\hline Glitazones & 0.20 & 0.20 & $-0.08(-0.22$ to 0.06$)$ & $1.14^{13}$ & -2.77 \\
\hline Lipid lowering drugs & 7.05 & 7.29 & $-0.17(-0.87$ to 0.53$)$ & $0.30^{13}$ & -1.55 \\
\hline Antihypertensive drugs & 7.50 & 7.21 & $-0.04(-0.48$ to 0.40$)$ & $0.14^{13}$ & -0.17 \\
\hline Aspirin & 4.43 & 4.45 & $0.21(-0.43$ to 0.84$)$ & $0.04^{13}$ & 0.26 \\
\hline Antidepressants & 1.11 & 1.02 & $0.10(-0.15$ to 0.34$)$ & $0.03^{13}$ & 0.09 \\
\hline TOTAL & & & & & -6.03 \\
\hline \multicolumn{6}{|c|}{ Use of NHS resources (mean number of visits) } \\
\hline General practitioner & 4.34 & 4.33 & $0.36(-0.29$ to 1.0$)$ & $30^{14}$ & 10.80 \\
\hline Nurse & 4.82 & 5.26 & $0.25(-0.45$ to 0.94$)$ & $8^{14}$ & 2.00 \\
\hline Physiotherapist & 0.81 & 0.43 & $-0.35(-0.82$ to 0.11$)$ & $16^{14}$ & -5.60 \\
\hline Podiatrist & 1.36 & 1.23 & $-0.19(-0.73$ to 0.35$)$ & $9^{14}$ & -1.71 \\
\hline Dietitian & 0.61 & 0.49 & $-0.15(-0.36$ to 0.07$)$ & $37^{14}$ & -5.55 \\
\hline Optician & 1.25 & 1.28 & $0.10(-0.09$ to 0.28$)$ & $38.35^{37}$ & 3.80 \\
\hline TOTAL & & & & & 3.74 \\
\hline
\end{tabular}

DESMOND, diabetes education and self management for ongoing and newly diagnosed.

*Intervention less control. Medication use calculation adjusted for clustering, baseline medication use, and corresponding baseline biomedical measure (glycated haemoglobin $\left(\mathrm{HbA}_{1 \mathrm{c}}\right)$ for oral hypoglycaemic agents; total cholesterol to high density lipoprotein cholesterol ratio for lipid lowering drugs; systolic blood pressure for antihypertensive drugs). Use of NHS resources adjusted for clustering, age, sex, ethnicity, and baseline covariates (body weight, smoking, $\mathrm{HbA}_{1 c}$, systolic blood pressure, lipid ratio, waist circumference, BMI, and use of oral hypoglycaemic agents, antihypertensive drugs, lipid lowering drugs, and antidepressants. 
Table 3|Difference between control and intervention in biomedical markers of cardiovascular disease at 12 months in the trial of the DESMOND programme

\begin{tabular}{lcc} 
& $\mathrm{n}$ & $\begin{array}{c}\text { Mean }(\mathbf{9 5 \%} \mathrm{Cl}) \text { cluster adjusted difference } \\
\text { (intervention - control) }\end{array}$ \\
\hline $\mathrm{HbA}_{1 \mathrm{c}}(\%)$ & 715 & $0.060(-0.097$ to 0.217$)$ \\
\hline Total cholesterol $(\mathrm{mmol} / \mathrm{l})$ & 709 & $-0.044(-0.201$ to 0.114$)$ \\
\hline High density lipoprotein cholesterol $(\mathrm{mmol} / \mathrm{l})$ & 526 & $0.015(-0.043$ to 0.073$)$ \\
\hline Systolic blood pressure $(\mathrm{mm} \mathrm{Hg})$ & 727 & $0.984(-1.800$ to 3.768$)$
\end{tabular}

DESMOND, diabetes education and self management for ongoing and newly diagnosed; $\mathrm{HbA}_{1 \mathrm{c}}$, glycated haemoglobin.

intervention, so we assumed that it was completely lost three years after the end of the intervention.

\section{Drug use}

The odds ratio for using an oral hypoglycaemic agent at month 12 was 0.79 . This was used to apply differential rates of oral hypoglycaemic agent use to the two treatment arms in the long term model. We assumed that the first line oral hypoglycaemic agent is metformin, after which a sulphonylurea is added, followed by switching to insulin plus metformin. Given that there was negligible difference between study arms in the rate of statin use at month 12 of the trial (odds ratio $=0.99)$, we applied the same rate $(75 \%)$ at baseline to the two arms in the long term model. There was a higher rate of antihypertensive therapy use at month 12 in the intervention arm, but this difference was not statistically significant (odds ratio $1.18,95 \%$ CI 0.71 to 1.98). This equates to only $4 \%$ higher usage in the intervention arm, equivalent to an additional cost of about $£ 2$, so we assumed equal rates of antihypertensive use in the long term model.

\section{Health related quality of life}

Health related quality of life data were recorded from trial participants using the EQ-5D questionnaire at baseline and at four, eight, and 12 months. The EQ$5 \mathrm{D}$ questionnaire uses five dimensions of health (mobility; self care; usual activities; pain and discomfort; and anxiety and depression), each of which is assessed by a single question and scored on a three point ordinal scale (no problems; some problems; or extreme problems). We combined the five dimension scores at each time period into a single preference score using the standard UK algorithm. ${ }^{17}$ The incremental gain in QALYs during the trial in patients who received the DESMOND intervention was $0.0070 \quad(95 \%$ CI -0.0126 to 0.0491 )

Table 4 | Likelihood of smoking at month 12 given baseline smoking status in the trial of the DESMOND programme

\begin{tabular}{lcc} 
& \multicolumn{2}{c}{$\begin{array}{c}\text { Conditional probability that individual smokes at month } 12 \text { (mean } \\
(95 \% \mathrm{Cl}))\end{array}$} \\
\cline { 2 - 3 } & \multicolumn{1}{c}{ Control } & Intervention \\
Smoker at baseline & $0.882(0.774$ to 0.990$)$ & $0.861(0.748$ to 0.974$)$ \\
\hline Non-smoker at baseline & $0.037(0.010$ to 0.064$)$ & 0 \\
\hline DESMOND, diabetes education and self management for ongoing and newly diagnosed. \\
\hline
\end{tabular}

The decrements in health related quality of life attributable to diabetes and complications of diabetes that we used in the long term model were based on UKPDS data where possible, ${ }^{18}$ with values for additional comorbidities obtained from Coffey et al. ${ }^{19}$ Utility changes associated with weight gain were based on a simple weighted average of two studies ${ }^{2021}$ - a 0.0025 (95\% CI 0.0003 to 0.0048 ) utility decrement per $\mathrm{kg}$ increase in weight. A recent review of weight and health related quality of life in patients with or without type 2 diabetes reported similar results. ${ }^{22}$

\section{Long term modelling}

The Sheffield type 2 diabetes model is an integrated individual level simulation model $^{23}$ that estimatesusing changes in key risk factors such as smoking status, $\mathrm{HbA}_{1 \mathrm{c}}$ level, lipid concentration, and blood pressure - the effect of alternative interventions on long term incidence of diabetic complications and mortality, and the associated economic effects of such interventions and outcomes. The model also includes side effects such as hypoglycaemic attacks and, importantly for this assessment, the ability to estimate the effect of weight changes on health related quality of life. A description of the Sheffield type 2 diabetes model and a model structure diagram appear in web extra 1 and web figure A, respectively.

The main outcome in our long term modelling was the incremental cost per QALY gained in patients who received the DESMOND intervention compared with those who received usual care. The time limit used for the long term modelling was 80 years (effectively lifetime for this age group).

The UKPDS coronary heart disease and stroke risk engines use smoking status at diagnosis of diabetes as a risk factor. ${ }^{2425}$ We assumed that current smoking status can be applied in these equations so that ongoing risk estimates of cardiovascular disease take account of changes in smoking status. Comparison of the hazard ratios from these risk engines with those from the UKPDS outcomes model ${ }^{26}$ (which uses current smoking status) suggests that this is a reasonable assumption. The effect of smoking on other cause mortality was based on the hazard ratio reported in the UKPDS outcomes model.

The mean characteristics of patients at entry to the long term model are shown in table 5 and reflect the mean adjusted differences between the intervention and the control (that is, adjustment was made to eliminate differences at baseline between the two study arms of the trial). Prevalence of atrial fibrillation was not obtained from the DESMOND data but assumed to be $1 \%$ on the basis of UKPDS data.

\section{Uncertainty and sensitivity analyses}

The approach to the handling of uncertainty was essentially Bayesian, with values being sampled from distributions for parameters (for example, $\mathrm{HbA}_{1 \mathrm{c}}$ level, weight) to capture uncertainty around the mean estimates. A probabilistic sensitivity analysis was conducted by combining 500 random samples from the 
trial results, obtained using bootstrapping, with 500 sample results from probabilistic sensitivity analysis each with a cohort size of 100 patients. ${ }^{27}$ This approach assumes that the incremental costs during the trial were independent of incremental costs from the long term model; likewise for incremental QALYs gained. This assumption was considered reasonable because economic outcomes arising during the trial are strongly driven by the effect of undertaking lifestyle changes during the trial, whereas economic outcomes from the long term model are more complex, with results being more driven by uncertainty in model parameters, such as the coefficients used in the cardiovascular risk equations. Probabilistic sensitivity analyses were undertaken using both trial and real world costs of delivering the DESMOND programme.

We also undertook a sensitivity analysis using more conservative assumptions, in particular concerning the durability of the effects of the DESMOND intervention observed at the end of the trial. Changes in biomarkers (including weight) were assumed to last for only one year from the end of the trial, smoking relapse rates were scaled up by $25 \%$, and a lower hazard ratio was assumed for other cause mortality due to smoking (1.24 $v 1.36$ for the base case analysis).

\section{RESULTS}

On the basis of our costing exercise, the estimated cost of delivering the DESMOND programme in the 12 month trial of the intervention was $£ 203$ per patient. The equivalent real world cost per patient for a hypothetical primary care trust was estimated to be

Table $5 \mid$ Characteristics derived from measures at month 12 of the trial of the DESMOND intervention that were used as inputs for the long term model

\begin{tabular}{|c|c|c|}
\hline & $\begin{array}{c}\text { Control (mean (SD) or } \\
\mathrm{n} / \mathrm{N}(\%))\end{array}$ & $\begin{array}{l}\text { Intervention (mean (SD) or } \\
\mathrm{n} / \mathrm{N}(\%))\end{array}$ \\
\hline Age (years) & $61(12)$ & $61(12)$ \\
\hline Sex (proportion male) & $26910 / 50000(54)$ & $26910 / 50000(54)$ \\
\hline $\begin{array}{l}\text { Smoking status (proportion who } \\
\text { smoke) }\end{array}$ & $8129 / 50000(16.3)$ & $6294 / 50000(12.6)$ \\
\hline $\begin{array}{l}\text { High density lipoprotein cholesterol } \\
(\mathrm{mmol} / \mathrm{l})\end{array}$ & $1.231(0.385)$ & $1.246(0.385)$ \\
\hline Total cholesterol $(\mathrm{mmol} / \mathrm{l})$ & $4.440(0.967)$ & $4.399(0.967)$ \\
\hline Systolic blood pressure (mm Hg) & $133.74(15.55)$ & $134.72(15.55)$ \\
\hline $\mathrm{HbA}_{1 \mathrm{c}}$ level (\%) & $6.64(0.96)$ & $6.70(0.96)$ \\
\hline \multicolumn{3}{|l|}{ Ethnic origin } \\
\hline White & $48623 / 50000(97)$ & $48623 / 50000(97)$ \\
\hline African-Caribbean & $467 / 50000(1)$ & $467 / 50000(1)$ \\
\hline Indian & $910 / 50000(2)$ & $910 / 50000(2)$ \\
\hline Time since diagnosis (years) & $1(0)$ & $1(0)$ \\
\hline Former smoker at diagnosis & $20010 / 50000(40)$ & $20543 / 50000(41)$ \\
\hline \multicolumn{3}{|l|}{ Therapy at entry } \\
\hline Diet and exercise & $29868 / 50000(59.7)$ & 31 032/50 000 (62.1) \\
\hline Metformin & $16283 / 50000(32.6)$ & 15 447/50 000 (30.9) \\
\hline $\begin{array}{l}\text { Metformin and sulphonylurea } \\
\text { combination }\end{array}$ & $3849 / 50000(7.7)$ & $3521 / 50000(7.0)$ \\
\hline \multicolumn{3}{|c|}{$\begin{array}{l}\text { DESMOND, diabetes education and self management for ongoing and newly diagnosed; } \mathrm{HbA}_{1 \mathrm{c}} \text {, glycated } \\
\text { haemoglobin. } \\
\text { Age and gender are the same in each arm because the aim of the modelling was to compare the long term } \\
\text { effects of the DESMOND programme with the effects of the control intervention in the same cohort. }\end{array}$} \\
\hline
\end{tabular}

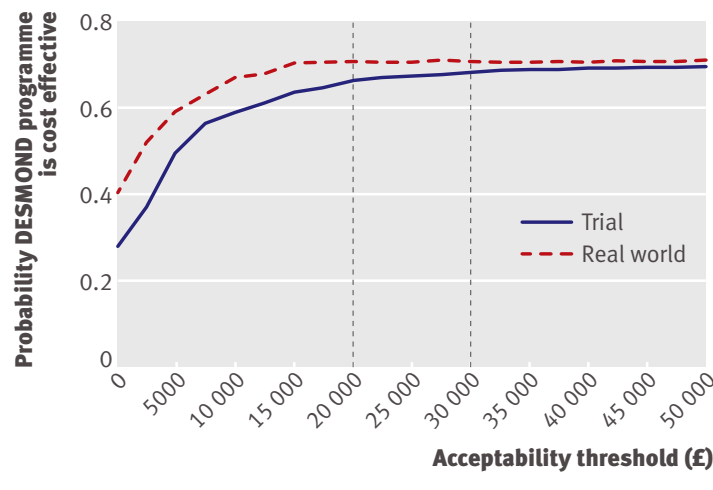

Fig 1| Cost effectiveness acceptability curves for the probability that the diabetes education and self management for ongoing and newly diagnosed (DESMOND) programme is more cost effective than usual care. The curves relate to the combined trial and long term modelling results, and are based on the cost of the DESMOND intervention during the trial and in the real world. The vertical dotted lines show the cost effectiveness acceptability thresholds of $£ 20000$ per QALY and $£ 30000$ per QALY

$£ 76$. Costs would vary, however, depending on local circumstances (for example, population size, pay scales of staff, number of staff trained). The cost of the DESMOND programme in terms of its effect on drug use and use of NHS resources was $£ 16$ in the trial, which differs from the sum of the two individual components shown in table 2 because of adjustment for clustering and covariates that were relevant to both drug and resource. Adding this value to the $£ 203$ cost of the intervention during the trial gives an estimated 12 month total incremental cost for the DESMOND intervention arm of $£ 219$. Using the $£ 76$ real world cost of the intervention, the total incremental cost was $£ 92$.

The results from the economic modelling are shown in table 6. Modelled lifetime costs - which incorporate drug costs, monitoring, and costs of complications from the end of month 12 to 80 years - are almost identical at $£ 15836$ in the control arm and $£ 15826$ in the intervention arm, a difference of just $£ 10$ (discounted). Therefore, the total lifetime cost of patients receiving the DESMOND intervention is $£ 16289$ using trial based intervention costs and $£ 16162$ using real world costs, $£ 209$ (95\% confidence interval $-£ 704$ to $£ 1137$ ) and $£ 82$ ( $-£ 831$ to $£ 1010)$ more expensive than usual care, respectively.

The mean cluster adjusted gain in QALY with the DESMOND programme up to month 12 in the trial is estimated at 0.0070 , equivalent to an average gain of 2.55 days of perfect health per person over the year. The long term gain in QALYs (end of month 12 to remaining lifetime) is estimated at 0.0322 , so the total estimated gain in QALYs for patients who received the DESMOND intervention compared with those who received usual care was 0.0392equivalent to a discounted average gain of 14.2 days of perfect health per person over their lifetime. The estimated incremental cost per QALY gained is 
Table 6 |Economic evaluation of the DESMOND intervention compared with usual care (control) using trial based costs and "real world" costs

\begin{tabular}{|c|c|c|c|}
\hline & Control & DESMOND intervention & $\begin{array}{l}\text { Difference: intervention - } \\
\quad \text { control }(95 \% \mathrm{Cl})\end{array}$ \\
\hline \multicolumn{4}{|l|}{ Intervention costs up to month 12} \\
\hline Trial based intervention cost & - & $£ 203$ & $£ 203$ \\
\hline "Real world" intervention cost & - & $£ 76$ & $£ 76$ \\
\hline $\begin{array}{l}\text { Other resource use (per within } \\
\text { trial analysis) }\end{array}$ & $£ 244$ & $£ 260^{*}$ & $£ 16(-£ 24$ to $£ 56)$ \\
\hline \multicolumn{4}{|c|}{ Remaining lifetime discounted costs } \\
\hline Therapy and monitoring & $£ 5286$ & $£ 5302$ & $£ 17$ \\
\hline Complications & $£ 10445$ & $£ 10419$ & $-£ 26$ \\
\hline $\begin{array}{l}\text { Adverse events (for example, } \\
\text { oedema, hypoglycaemic } \\
\text { attacks) }\end{array}$ & $£ 105$ & $£ 104$ & $-£ 1$ \\
\hline $\begin{array}{l}\text { Subtotal: remaining lifetime } \\
\text { costs }\end{array}$ & $£ 15836$ & $£ 15826$ & $-£ 10$ \\
\hline \multicolumn{4}{|l|}{ Combined total lifetime costs } \\
\hline Trial based total costs & $£ 16080$ & $£ 16289$ & $£ 209(-£ 704$ to $£ 1137)$ \\
\hline "Real world" total costs & $£ 16080$ & $£ 16162$ & $£ 82(-£ 831$ to $£ 1010)$ \\
\hline QALY gain up to month 12 & 0.7530 & $0.7600 \dagger$ & $\begin{array}{c}0.0070(-0.0126 \text { to } \\
0.0491)\end{array}$ \\
\hline \multicolumn{4}{|c|}{ Discounted QALYs in remaining lifetime } \\
\hline Mean QALYs lived if not diabetic & 13.9195 & 13.9195 & 0 \\
\hline $\begin{array}{l}\text { QALYs lost because of reduced } \\
\text { survival related to diabetes }\end{array}$ & -4.2809 & -4.2526 & $0.0283 \ddagger$ \\
\hline $\begin{array}{l}\text { QALYs lost because of } \\
\text { complications of diabetes }\end{array}$ & -0.3835 & -0.3833 & 0.0002 \\
\hline Weight related change in QALYS & -0.0447 & -0.0410 & 0.0037 \\
\hline $\begin{array}{l}\text { Subtotal: QALYs in remaining } \\
\text { lifetime }\end{array}$ & 9.2104 & 9.2426 & 0.0322 \\
\hline $\begin{array}{l}\text { Combined total QALYs gained in } \\
\text { lifetime }\end{array}$ & 9.9634 & 10.0026 & $\begin{array}{c}0.0392(-0.0813 \text { to } \\
0.1786)\end{array}$ \\
\hline \multicolumn{4}{|l|}{ Incremental cost per QALY gained } \\
\hline Trial based total costs & - & - & $£ 5387$ \\
\hline "Real world" total costs & - & - & $£ 2092 \S$ \\
\hline
\end{tabular}

DESMOND, diabetes education and self management for ongoing and newly diagnosed; QALY, quality adjusted life year.

*Other resource use shown as actual cost in control arm plus $£ 16$ for the cluster adjusted difference between study arms.

TQALY gain up to month 12 shown as actual QALYs in control arm plus 0.0070 for the cluster adjusted difference between study arms.

‡Difference in QALYs lost because of reduced survival related to diabetes attributable mostly to the net effect of differences in smoking on other cause and cardiovascular mortality.

$\S$ See the cost effectiveness plane in figure 2[F2] for the distribution of cost effectiveness estimates.

$£ 5387$ using trial based intervention costs and $£ 2092$ using real world costs. Such estimates are well within the threshold of $£ 20000$ to $£ 30000$ per QALY usually considered by the National Institute for Health and Clinical Excellence and other bodies as cost effective.

\section{Uncertainty analysis}

The cost effectiveness acceptability curves (fig 1) show that the probability of the DESMOND programme being more cost effective than usual care is fairly similar whether trial or real world intervention costs are used. Using trial costs, the probability of the DESMOND programme being more cost effective than usual care is 0.66 for an acceptability threshold of $£ 20000$ per QALY (0.68 for a threshold $£ 30000$ per QALY). Using real world costs, the probability is 0.70 for both an acceptability threshold of $£ 20000$ and a threshold of $£ 30000$ per QALY. The probability of the DESMOND programme being cost saving in the long term is 0.28 using trial costs and 0.40 using real world costs. The probability of the DESMOND programme resulting in long term gains in QALYs is 0.70 and 0.71 using trial and real world costs, respectively.

The probabilistic sensitivity analysis results presented in figure 2 show the spread of the real world cost effectiveness estimates on a plane. Although neither the mean incremental cost nor the mean incremental QALYs reach an arbitrary 5\% significance level, the probability of an intervention being cost effective is determined from a joint assessment of incremental costs and incremental QALYs. On the plane, $70 \%$ of the sampled data lie within the cost effective region to the right of the cost effectiveness "frontier," indicating a probability of the DESMOND intervention being cost effective of 0.7 .

\section{Sensitivity analysis}

The sensitivity analysis, which adopted a more conservative assumption relating to the durability of the effects observed at the end of the trial and a lesser effect of smoking on other cause mortality, did not change the results substantially. The incremental cost per QALY using the real world intervention costs was actually marginally lower than in the original analysis, at $£ 1618$ compared with $£ 2092$, with a 0.71 probability of cost effectiveness.

\section{DISCUSSION}

\section{Principal findings}

Taking account of simulated longer term effects, there is a $66 \%$ likelihood that the DESMOND intervention as delivered during the trial of the intervention is cost effective. Furthermore, the intervention is even cheaper as currently implemented in the real world, costing $£ 76$ per patient compared with $£ 203$ each in the trial. This disparity is a result of economies of scale and some unavoidable high costs during the trial (for example, residential courses were required to train educators attending from across the country). As such, the likelihood that the DESMOND programme is cost effective in the real world is, at 70\%, higher than in the trial. When the analysis was restricted to the costs and benefits within the 12 month time frame of the trial, the DESMOND intervention does not appear to be cost effective, as is often the case for an intervention aimed at preventing the long term effects of a chronic disease, although there is much uncertainty around the results.

Our results suggest that the DESMOND intervention is likely to be cost effective compared with usual care, especially with respect to the current cost of the intervention to primary care trusts. However, concluding that the intervention is likely to be cost effective despite the relatively small (and not all statistically significant) trial outcomes in terms of between group differences is at first sight counterintuitive. In order to make this conclusion, it is necessary to take into account both the size and the likelihood of health 
gains. Firstly, the nature of the intervention should be taken into account - that is, the DESMOND programme targets multiple risk factors. As such, it is the overall benefit of what are often small changes that needs to be considered. The collective mean estimated benefit of the changes arising from the DESMOND intervention is sufficient to outweigh the low intervention cost per patient. Indeed, the estimated mean health gains as measured by QALYs gained are equivalent to half a month of full health, an economically adequate return for a low cost investment. In other disease areas, treatments can cost tens of thousands of pounds per patient for the equivalent of several months QALY gains. Secondly, the likelihood of the intervention being cost effective, in this case $70 \%$, reflects the methods of economic evaluation, which, rather than focusing on type 1 or type 2 errors, consider the costs and health gains simultaneously.

The most economically significant benefits of the DESMOND programme are reductions in overall cardiovascular risk (mainly resulting from reduced smoking rates, as shown in table 4 , but also improvements to lipids, as shown in table 3), leading to greater survival. Together with a reduction in weight, these benefits lead to economically significant gains in QALYs (as shown in table 6).

It is interesting that the sensitivity analysis reduced the cost of the DESMOND programme per QALY gained. One might expect the more conservative set of assumptions used in the sensitivity analysis to

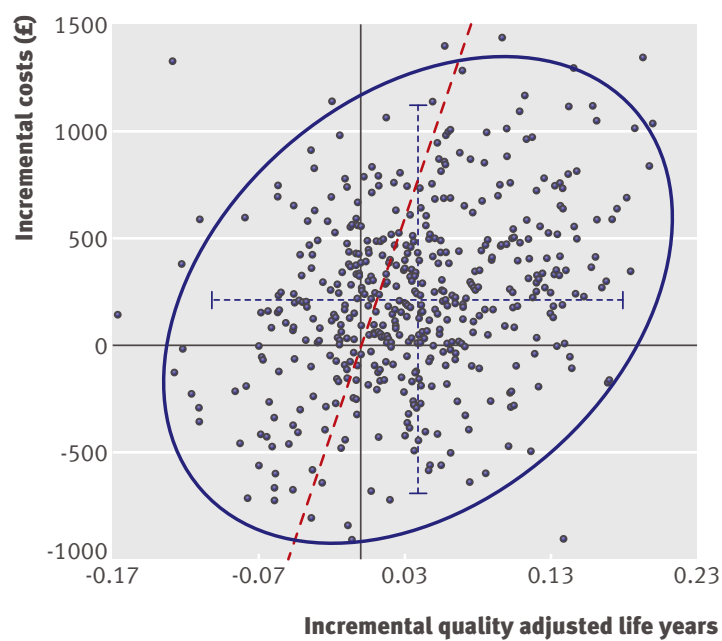

Fig 2 |Cost effectiveness plane for the combined trial and "real world" costs of the diabetes education and self management for ongoing and newly diagnosed (DESMOND) programme. Solid points represent incremental cost and QALY results (intervention arm minus control arm) from the probabilistic sensitivity analysis for each of the $\mathbf{5 0 0}$ samples. The dashed horizontal and vertical blue lines show the $95 \%$ confidence interval for the incremental costs and the $95 \%$ confidence interval for the incremental gains in quality adjusted life years. The blue curve is the $95 \%$ confidence ellipse. All points to the right of the diagonal dashed red line, or "frontier," are cost effective at an acceptability threshold of $£ 20000$ per quality adjusted life year increase rather than decrease the intervention cost per QALY gained. The main reason for this slightly counterintuitive result is that the more conservative assumptions reduce the incremental cost difference between the intervention and control arms. This is because, in the sensitivity analysis, a lower hazard ratio was assumed for other cause mortality due to smoking, resulting in extended survival in both study arms. The additional survival benefit was greater in the control patients as there were more smokers in this arm, resulting in greater exposure to the risk of complications, which require costly treatments.

\section{Strengths and limitations of the study}

Our analysis uniquely represents a detailed long term economic evaluation of a structured education programme based on results from a UK based randomised controlled trial that was carried out in accordance with a robust evaluation framework. ${ }^{28}$ Given that this was a large multi-site trial, the results are more representative than if we had used single centre studies.

The main areas of uncertainty around the results concern the effect of smoking on mortality and the durability of benefits such as improved rates of smoking and weight loss. For some risk factors used in the long term model, the differences between treatment groups were relatively small or were not statistically significant. Nevertheless, uncertainty around such effects is captured within the results of the probabilistic sensitivity analysis, and the benefits reported are economically significant when set against the low cost of the intervention. Furthermore, a sensitivity analysis that assumed the benefits only last for one year beyond the end of the 12 month trial and applied a lesser effect of smoking on mortality still showed a $71 \%$ likelihood that the intervention is cost effective.

\section{Comparison with other studies}

There are few other studies against which meaningful comparisons can be made because of the heterogeneity of the interventions across studies (for example, different amounts of education provided by various health professionals; different timing of the intervention relative to diagnosis of diabetes) and lack or limitations of economic evaluations in type 2 diabetes.

A review for the National Institute for Health and Clinical Excellence on the use of patient education models ${ }^{29}$ reported an evaluation of the Dose Adjustment For Normal Eating (DAFNE) intervention for type 1 diabetes. The review concluded that the intervention is both cost saving and generates health benefits compared with conventional treatment, even under modified conservative assumptions adopted by the technology assessment group. A recent review of the clinical effectiveness of diabetes education models for type 2 diabetes ${ }^{30}$ describes two studies in the United States that were considered to be limited in their applicability and generalisability. The review did not draw any conclusions on the overall cost effectiveness of the education models. Another recent review focusing on the cost effectiveness of diabetes education ${ }^{31}$ refers 


\section{WHAT IS ALREADY KNOWN ON THIS TOPIC}

The diabetes education and self management for ongoing and newly diagnosed (DESMOND) intervention for people with newly diagnosed type 2 diabetes is a one off education programme that meets all the quality criteria for education programmes specified by the National Institute for Health and Clinical Excellence

The DESMOND programme has been shown to be associated with benefits in illness beliefs, weight loss, physical activity, smoking status, and depression but not in haemoglobin $A_{1 c}$ levels

To date, there has been no economic evaluation of the DESMOND intervention to assess whether the benefits reported in the previous trial represent a cost effective return for the programme compared with usual care

\section{WHAT THIS STUDY ADDS}

The cost of delivering the intervention is estimated at $£ 203$ per patient on the basis of costs in the previous trial and $£ 76$ on the basis of "real world" costs estimated for a hypothetical primary care trust

The estimated incremental cost per quality adjusted life year (QALY) gained is $£ 5387$ using the trial based costs and £2092 using real world costs

The probability that the DESMOND intervention is cost effective in the long term using a cost effectiveness acceptability threshold of $£ 20000$ ( $€ 23$ 982; \$31 191) per QALY is 0.66 for trial based costs of delivery and 0.70 for real world costs to several economic studies involving differing amounts of education provided by various health professionals. The authors conclude that diabetes education is likely to be cost effective, especially when provided to patients with the poorest glycaemic control.

Two other well known diabetes education studies, the Turin study ${ }^{32}$ and the Expert Patient Education versus Routine Treatment (XPERT) programme, ${ }^{33}$ assessed patients with established type 2 diabetes. However, economic evaluations of these studies have not been undertaken. The need to offer optimal intervention from diagnosis in patients with diabetes is supported by the legacy effect observed from the long term follow-up data of the UKPDS. ${ }^{34}$

\section{Unanswered questions and future research}

Although it is likely that the one off DESMOND intervention is cost effective, it must be noted that the DESMOND programme was never intended as a one off intervention. An ongoing model of education and care is currently being developed, which will provide reinforcement at additional points of contact and an optimal environment for improving patient outcomes from education, as discussed by Loveman and colleagues. ${ }^{30}$ Diabetes prevention trials have shown that with reinforcement, benefits such as weight loss can be sustained over a period of several years in many patients. $^{35}$

The independent effects of some changes in biomedical and other measures on health related quality of life (and comorbidities) are unknown. For example, the DESMOND programme had a favourable effect on symptoms of depression, as measured by the hospital anxiety and depression (HADS) score. It is likely that this effect would result in some economic benefits beyond the trial that are not included in our results; for example, in terms of reduced use of health care, improved quality of life, or both. In addition, the intervention group also achieved a greater fall in triglyceride concentration at month 12 than the control group (a measure that is not captured within the UKPDS cardiovascular disease risk equations) and a more positive change in illness beliefs about diabetes (although the extent to which this is captured by utility instruments such as the EQ-5D warrants further investigation).

No significant effect of the DESMOND intervention on the amount of time spent with healthcare professionals was observed during the trial. Potentially, improved skills in self care might reduce the need for patients with diabetes to seek advice from NHS professionals, although an increased awareness following participation in the DESMOND programme might help patients make better use of opportunities for advice seeking and more appropriate visits to primary healthcare clinicians, as well as improve compliance with drug and prescribed therapies.

As with other lifestyle programmes, such as those to prevent diabetes, there will be considerable variability across patients in their response to the DESMOND intervention. Greater understanding of how to lessen physiological and motivational barriers in non-responsive individuals would help to improve the effectiveness of the intervention in a broad mix of patients.

The real world costs of delivering the DESMOND programme are likely to vary considerably across primary care trusts. The main variables affecting the cost are the number of educators trained, the grade of healthcare professional delivering courses, venue cost, ratio of demand to head of population (including participation rate), number of patients per course, and overhead rates. There is a continuum of delivery costs associated with delivering the intervention, ranging from running the intervention extremely efficiently (for example, training a small number of educators and having them deliver the DESMOND programme full time) to running it less efficiently (for example, with a high ratio of educators to course sessions). These factors need to be considered when setting up a cost effective DESMOND programme.

\section{Conclusions and policy implications}

We conclude, on the basis of the results of a randomised controlled trial of the intervention and estimated costs of delivery in the real world, that the DESMOND programme is a low cost and likely cost effective intervention for patients with newly diagnosed type 2 diabetes. People attending DESMOND sessions are encouraged to decide on their own goals, which often include weight loss and smoking cessation. These outcomes were both significantly improved in the trial and were the most important drivers in the economic analysis. Although $\mathrm{HbA}_{1 \mathrm{c}}$ level was not improved in the trial of the DESMOND intervention, this may have been because the major improvements in $\mathrm{HbA}_{1 \mathrm{c}}$ level achieved in the period after diagnosis of diabetes, as seen in both study arms, may have masked any effect 
of the intervention. ${ }^{36}$ Maintenance of these benefits is important for reducing the risk of cardiovascular disease and improving quality of life. Our analysis indicates that the DESMOND programme is likely to be a cost effective form of structured education that should be given in line with National Institute for Health and Clinical Excellence guidance. ${ }^{5}$

Contributors: MG carried out the statistical analysis with advice and assistance from MJC, P Fitzgerald, and T Young. MG carried out the economic analysis with advice from SD and AB. HMD, MEC, SH, KK, and MJD assisted with the costing of the intervention. MG wrote the paper with assistance from HMD, SD, AB, MEC, MJC, SH, KK, TCS, and MJD. TCS $\mathrm{SH}, \mathrm{MEC}, \mathrm{KK}$, and MJD are the principal investigators of the DESMOND study. All authors had full access to all of the data in the study (including statistical reports and tables) and can take responsibility for the integrity of the data and the accuracy of the data analysis. MG is the guarantor. Funding: The study was funded by a grant from Diabetes UK secured by the University Hospitals of Leicester NHS Trust. The analysis was independently designed and undertaken by the University of Sheffield School of Health and Related Research and collaborators. Researchers worked independently from the funders. Similarly the writing of the report and the decision to submit the article for publication was entirely independent of the funder. The study funder had no input into the study design or analysis, nor the interpretation of data.

Competing interests: All authors have completed the Unified Competing Interest form at www.icmje.org/coi_disclosure.pdf (available on request from the corresponding author) and declare: no support from any company for the submitted work; no financial relationships with any companies that might have an interest in the submitted work in the previous 3 years; no other relationships or activities that could appear to have influenced the submitted work.

Ethical approval: The study was approved by the Huntingdon local research ethics committee.

Data sharing: No data from the original DESMOND trial is currently available for sharing at this moment in time.

1 International Diabetes Federation. IDF diabetes atlas-prevalence estimates of diabetes mellitus. 2007. www.eatlas.idf.org.

2 Massi-Benedetti M. The cost of diabetes type II in Europe: the CODE2 study. Diabetologia 2002;45:1-4S

3 Nathan DM, Buse JB, Davidson MB, Ferrannini E, Holman RR, Sherwin R, et al for the European Association for Study of Diabetes. Medical management of hyperglycemia in type 2 diabetes: a consensus algorithm for the initiation and adjustment of therapy. A consensus statement of the American Diabetes Association and the European Association for the Study of Diabetes. Diabetes Care 2009;32:193-203.

4 Morris AD. Considerations in assessing effectiveness and costs of diabetes care: lessons from DARTS. Diabetes Metab Res Rev 2002;18(suppl 3):32-5S.

5 National Institute for Health and Clinical Excellence. Clinical guideline 87. Type 2 diabetes: the management of type 2 diabetes (partial update). NICE, 2009.

6 Davies MJ, Heller S, Skinner TC, Campbell MJ, Carey ME, Cradock S, et al for the Diabetes Education and Self Management for Ongoing and Newly Diagnosed Collaborative. Effectiveness of the diabetes education and self management for ongoing and newly diagnosed (DESMOND) programme for people with newly diagnosed type 2 diabetes: cluster randomised controlled trial. BMJ 2008;336:491-5.

7 Khunti K, Skinner TC, Heller S, Carey ME, Dallosso HM, Davies MJ for the DESMOND Collaborative. Biomedical, lifestyle and psychosocial characteristics of people newly diagnosed with type 2 diabetes: baseline data from the DESMOND randomized controlled trial. Diabet Med 2008;25:1454-61.

8 Skinner TC, Carey ME, Cradock S, Daly H, Davies MJ, Doherty Y, et al. Diabetes education and self-management for ongoing and newly diagnosed (DESMOND): process modelling of pilot study. Patient Educ Couns 2006;64:369-77.

9 National Institute for Health and Clinical Excellence. Guide to the methods of technology appraisal. NICE, 2008.

10 Campbell MJ. Cluster randomized trials in general (family) practice research. Stat Methods Med Res. 2000;9:81-94.

11 Campbell M), Donner A, Klar N. Developments in cluster randomized trials and statistics in medicine. Stat Med 2007;26:2-19.
12 Harrell FE, Margolis PA, Gove S, Mason KE, Mulholland EK, Lehmann L, et al. Development of a clinical prediction model for an ordinal outcome: the World Health Organization ARI multicentre study of clinical signs and etiologic agents of pneumonia, sepsis and meningitis in young infants. Stat Med 1998;17:90-144.

13 The NHS Information Centre for Health and Social Care (Prescribing Support Unit). Prescription cost analysis for England 2007. The NHS Information Centre, 2008.

14 Curtis L; Personal Social Services Research Unit. Unit costs of health and social care. PSSRU, 2007.

15 Clarke P, Gray A, Legood R, Briggs A, Holman R. The impact of diabetes-related complications on healthcare costs: results from the United Kingdom Prospective Diabetes Study (UKPDS study number 65). Diabet Med 2003;20:442-50.

16 Hawkins, J. Long term smoking relapse: a study using the British household panel survey [dissertation]. Department of Economics: University of Sheffield, 2007.

17 Dolan P. Modeling valuations for EuroQol health states. Med Care 1997:35:1095-108.

18 Clarke P, Gray A, Holman R. Estimating utility values for health state of type 2 diabetic patients using the EQ-5D (UKPDS 62). Med Decis Making 2002;22:340-9.

19 Coffey JT, Brandle M, Zhou H, Marriott D, Burke R, Tabaei BP, et al. Valuing health-related quality of life in diabetes. Diabetes Care 2002;25:2238-43.

20 Warren E, Brennan A, Akehurst R. Cost-effectiveness of sibutramine in the treatment of obesity. Med Decis Making 2004;24:9-19.

21 O'Meara S, Riemsma R, Shirran L, Mather L, ter Riet G. The clinical effectiveness and cost-effectiveness of sibutramine in the management of obesity: a technology assessment. Health Technol Assess 2002;6:1-97.

22 Dennett SL, Boye KS, Yurgin NR. The impact of body weight on patien utilities with or without type 2 diabetes: a review of the medical literature. Value Health 2008;11:478-86.

23 Brennan A, Chick SE, Davies R. A taxonomy of model structures for economic evaluation of health technologies. Health Econ 2006;15:1295-310.

24 Stevens RJ, Kothari V, Adler AI, Stratton IM for the United Kingdom Prospective Diabetes Study (UKPDS) Group. The UKPDS risk engine: a model for the risk of coronary heart disease in type 2 diabetes (UKPDS 56). Clin Sci 2001;101:671-9.

25 Kothari V, Stevens RJ, Adler AI, Stratton IM, Manley SE, Neil HAW, et al. UKPDS 60: risk of stroke in type 2 diabetes estimated by the UK Prospective Diabetes Study risk engine. Stroke 2002;33:1776-81.

26 Clarke PM, Gray AM, Briggs A, Farmer AJ, Fenn P, Stevens RJ, et al. A model to estimate the lifetime health outcomes of patients with type 2 diabetes: the United Kingdom Prospective Diabetes Study (UKPDS) outcomes model (UKPDS number 68). Diabetologia 2004;47:1747-59.

27 O'Hagan A, Stevenson M, Madan J. Monte Carlo probabilistic sensitivity analysis for patient level simulation models: efficient estimation of mean and variance using ANOVA. Health Econ 2007;16:1009-23.

28 Campbell M, Fitzpatrick R, Haines A, Kinmonth AL, Sandercock P, Spiegelhalter D, et al. Framework for design and evaluation of complex interventions to improve health. BMJ 2000;321:694-6.

29 National Institute for Clinical Excellence. Guidance on the use of patient-education models for diabetes. Technology appraisal 60 . NICE, 2003.

30 Loveman E, Frampton GK, Clegg AJ. The clinical effectiveness of diabetes education models for type 2 diabetes-a systematic review. Health Technol Assess 2008;12:1-116.

31 Urbanski P, Wolf A, Herman WH. Cost-effectiveness of diabetes education. J Am Diet Assoc 2008;108(suppl 1):6-11S.

32 Trento M, Passera P, Borgo E, Tomalino M, Bajardi M, Cavallo F, et al. A 5-year randomized controlled study of learning, problem solving ability, and quality of life modifications in people with type 2 diabetes managed by group care. Diabetes Care 2004;27:670-5.

33 Deakin TA, Cade JE, Williams R, Greenwood DC. Structured patient education: the diabetes X-PERT programme makes a difference. Diabet Med 2006;23:944-54.

34 Holman RR, Paul SK, Bethel MA, Matthews DR, Neil HA. 10-year follow-up of intensive glucose control in type 2 diabetes. $N$ Engl Med 2008;359:1577-89.

35 Lindström J, Peltonen M, Tuomilehto J. Lifestyle strategies for weight control: experience from the Finnish Diabetes Prevention Study. Proc Nutr Soc 2005;64:81-8.

36 Dinneen S. Structured education for people with type 2 diabetes. $B M / 2008 ; 336: 459-60$

Accepted: 20 May 2010 